\title{
Association of feeding modality with interstage mortality after single-ventricle palliation
}

\author{
Camden L. Hebson, MD, ${ }^{\text {a }}$ Matthew E. Oster, MD, MPH, ${ }^{a}$ Paul M. Kirshbom, MD, ${ }^{b}$ Martha L. Clabby, MD, ${ }^{a}$ \\ Mark L. Wulkan, MD, ${ }^{\mathrm{c}}$ and Janet M. Simsic, MD $^{\mathrm{a}}$
}

Objective: Interstage mortality has been reported in $10 \%$ to $25 \%$ of hospital survivors after single-ventricle palliation. The purpose of this study was to examine the impact of feeding modality at discharge after single-ventricle palliation on interstage mortality.

\begin{abstract}
Methods: We conducted a retrospective review of all neonates undergoing single-ventricle palliation from January 2003 to January 2010. A total of 334 patients (90\%) survived to hospital discharge, comprising the study group. Preoperative, operative, and postoperative variables were examined, including feeding method at discharge. Multivariate Poisson regression models were constructed to estimate the relative risk of interstage mortality.
\end{abstract}

Results: Of 334 patients, $56(17 \%)$ underwent gastrostomy tube \pm Nissen. There was a statistically significant increase in interstage mortality for patients who underwent gastrostomy tube \pm Nissen compared with patients who did not (relative risk, $2.38 ; 95 \%$ confidence interval, $1.05-5.40 ; P=.04]$ ). Of the 278 patients who were not fed via a gastrostomy tube \pm Nissen, $190(68 \%)$ were fed with nasogastric feedings and $88(32 \%)$ were fed entirely by mouth. There was no difference in interstage mortality between these 2 groups (relative risk, $0.92 ; 95 \%$ confidence interval, $0.31-2.73 ; P=.89$ ).

Conclusions: Neonates undergoing single-ventricle palliation who require gastrostomy tube \pm Nissen are at an increased risk of interstage mortality. The need for gastrostomy tube \pm Nissen in this population may be a marker for other unmeasured comorbidities that place them at an increased risk of interstage mortality. Discharge with nasogastric feeds does not increase the risk of interstage mortality. (J Thorac Cardiovasc Surg 2012;144:173-7)

Interstage mortality has been shown in $10 \%$ to $25 \%$ of hospital survivors after single-ventricle palliative cardiac surgery. ${ }^{1-6}$ Respiratory infection, ${ }^{7,8}$ sepsis, ${ }^{5,8}$ coronary obstruction, ${ }^{9}$ aortic arch obstruction, ${ }^{8,10}$ low cardiac output, ${ }^{5,8,11}$ arrhythmia, ${ }^{6}$ and sudden unexplained cardiac death ${ }^{6-8}$ have been reported as potential causes. After single-ventricle palliation, patients frequently have difficulty feeding per os (PO), which is often attributed to lack of preoperative feeding, poor oromotor skills, gastroesophageal reflux, and congestive heart failure, among other problems. ${ }^{12}$ Because of these issues, alternative methods of enteral feeding are commonly used, that is, nasogastric tube (NG), gastrostomy tube (GT), or Nissen fundoplication and gastrostomy tube (Nissen/GT). Limited data exist on the impact of these alternative feeding modalities on interstage mortality. Thus, variation in clinical practice is the norm.

\footnotetext{
From the Sibley Heart Center, ${ }^{\text {a }}$ Children's Healthcare of Atlanta, Ga; and Divisions of Cardiothoracic Surgery ${ }^{\mathrm{b}}$ and Pediatric Surgery, ${ }^{\mathrm{c}}$ Department of Surgery, Emory University School of Medicine, Atlanta, Ga.

Disclosures: Authors have nothing to disclose with regard to commercial support.

Received for publication Aug 15, 2011; revisions received Oct 21, 2011; accepted for publication Dec 14, 2011; available ahead of print Jan 13, 2012.

Address for reprints: Camden L. Hebson, MD, 2835 Brandywine Road, Atlanta, GA 30341-5510 (E-mail: chebson@emory.edu).

$0022-5223 / \$ 36.00$

Copyright (C) 2012 by The American Association for Thoracic Surgery doi:10.1016/j.jtcvs.2011.12.027
}

The purpose of this study was to evaluate the association of feeding route at the time of discharge with interstage mortality after single-ventricle palliation. We hypothesized that (1) patients who received a Nissen/GT would be at a lower risk of interstage mortality because of protection against aspiration-related death and that (2) there would be no difference in mortality between PO and NG feeding in patients.

\section{MATERIALS AND METHODS Patient Population}

We conducted a retrospective cohort study of all neonates (aged $<30$ days at time of surgery) undergoing a single-ventricle palliative procedure (Norwood operation, pulmonary artery band, or modified Blalock-Taussig shunt) from January 2003 to January 2010 at a single institution. A total of 372 total neonates were identified. Thirty-eight neonates who died after single-ventricle palliation before hospital discharge were excluded from further analysis. End points for our analysis were completion of a second palliative operation (or in some cases a complete surgical repair) or death before the second surgery. Therefore, 334 patients meeting entrance criteria comprised the study group. This retrospective review was performed with approval of the institutional review board at Children's Healthcare of Atlanta with waiver of informed consent.

\section{Study Variables}

Our primary outcome of interest was interstage mortality, defined as death between hospital discharge after single-ventricle palliation and second-stage procedure. Our primary predictor variable of interest was feeding modality at time of discharge. We performed separate analyses 


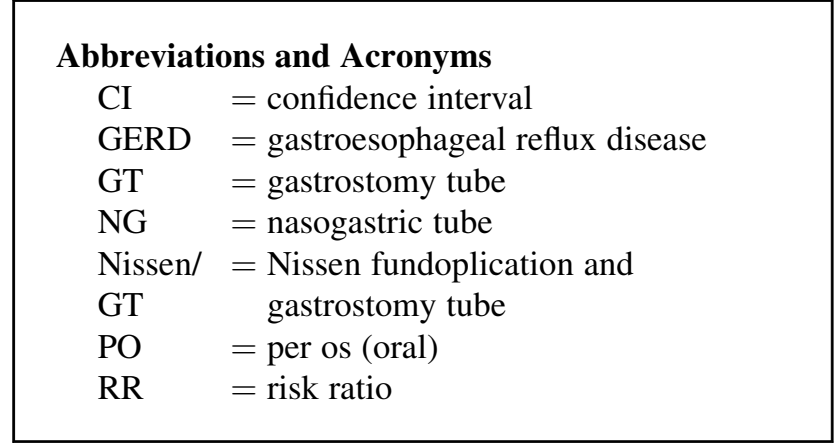

for 1) those with a Nissen/GT versus those without a Nissen/GT and 2) those discharged with any nasogastric (NG) feeds versus those discharged with all PO feeds. For these analyses, the patients who received a GT alone were included in the Nissen/GT group. The patients in the NG group included those fed entirely with NG feeds and those who were fed with hybrid $\mathrm{PO} / \mathrm{NG}$ feeds. Our primary covariates of interest were preoperative, operative, and postoperative variables that could affect interstage mortality. Age, weight, prematurity, ${ }^{13}$ genetic abnormality, ${ }^{7}$ heterotaxy, ${ }^{7}$ arrhythmia, ${ }^{6}$ and decreased systemic ventricular function ${ }^{14}$ were specifically included in the multivariate analysis to control for known risk factors for interstage death. Prematurity was defined as less than 37 weeks gestation. Genetic abnormality was defined as dysmorphic appearance in the opinion of a consulting geneticist (consult obtained if clinical suspicion was high) or abnormal genetic testing. An arrhythmia was defined as any tachyarrhythmia or bradyarrhythmia that required medical intervention and occurred before discharge. Single-ventricle function was described as decreased or normal on the basis of qualitative interpretation of the discharge echocardiogram. Finally, although no standard algorithm for pursuing a Nissen/GT exists at Children's Healthcare of Atlanta, every patient who underwent the procedure had clinically significant gastroesophageal reflux disease (GERD) that failed medical therapy, plus failure to thrive $(31 \%)$ or aspiration $(69 \%)$ as the primary indications for surgery. A GT without a Nissen was only placed if no significant GERD was suspected. All patients underwent an upper gastrointestinal fluoroscopy study before the procedure, and $39 \%$ of patients received a $\mathrm{pH}$ probe (at the discretion of the pediatric general surgeon and cardiothoracic surgeon).

\section{Statistical Analysis}

For each of our analysis groups, (1) Nissen/GT versus no Nissen/GT and (2) any NG versus entirely PO, we first compared baseline categoric variables using chi-square tests and baseline continuous variables using $t$ tests. We then constructed multivariate Poisson regression models adjusting for the covariates listed above to estimate the relative risk of interstage mortality for each comparison group. To assess whether there was a difference in relative risk for those with or without a Norwood operation, we then performed separate stratified analyses in these 2 populations. From the regression models, we calculated adjusted risk ratios (RRs) and $95 \%$ confidence intervals (CIs). All analyses were performed using SAS Version 9.2 (SAS Institute, Inc, Cary, NC). Data are expressed as mean values \pm standard deviations.

\section{RESULTS}

In this cohort study, 165 patients underwent a Norwood operation, 17 patients underwent a pulmonary artery band, and 152 patients underwent a Blalock-Taussig shunt. The underlying anatomy of the study group is shown in Table 1.
TABLE 1. Underlying anatomic diagnoses $(n=334)$

\begin{tabular}{lc}
\hline \multicolumn{1}{c}{ Anatomic diagnosis } & $\begin{array}{c}\text { Percentage of } \\
\text { total study group }\end{array}$ \\
\hline Hypoplastic left heart syndrome & $31 \%$ \\
Tricuspid atresia & $9 \%$ \\
Unbalanced atrioventricular canal & $6 \%$ \\
Heterotaxy single-ventricle variant & $6 \%$ \\
Double-inlet left ventricle & $6 \%$ \\
Pulmonary atresia with a ventriculoseptal defect & $10 \%$ \\
Pulmonary atresia with intact ventricular septum & $15 \%$ \\
Tetralogy of Fallot & $4 \%$ \\
Transposition of the great arteries with pulmonic & $6 \%$ \\
$\quad$ stenosis & \\
Other & $7 \%$ \\
\hline
\end{tabular}

\section{Nissen/Gastrostomy Tube Versus No Nissen/ Gastrostomy Tube}

Among the 334 study patients, 56 underwent a Nissen/ GT or GT alone (Nissen/GT in 42 and GT alone in 14). Complete comparisons between these patients and all other patients are shown in Table 2. The results of multivariate analysis, constructed using previously published risk factors for interstage mortality, are shown in Table 3. The adjusted relative risk of interstage mortality for those patients with single-ventricle physiology with a Nissen/GT versus those without a Nissen/GT was $2.38(95 \% \mathrm{CI}$, $1.05-5.40 ; P=.04)$. In the stratified analyses, this estimated relative risk of interstage mortality for those with a Nissen/ GT versus those without a Nissen/GT was similar in both the Norwood group (RR, 2.24) and the non-Norwood group (RR, 2.10).

Because of the unexpected finding of increased risk of interstage mortality in the patients who underwent Nissen/ GT, we evaluated our inpatient post-Nissen experience. Fifty-six $(96 \%)$ of the 58 patients who underwent a Nissen/GT survived to hospital discharge. One inpatient death was remote from surgery and occurred during attempted operative removal of a large pericardial clot. The other death occurred within hours of Nissen/GT surgery and manifested as a bradycardiac event followed by unsuccessful resuscitation; no autopsy was performed. Other complications included 1 failed Nissen wrap that was redone 5 months after the original surgery, 1 prolonged intubation postoperatively, 3 procedures that were converted from laparoscopic to open (thus with longer recovery time), and 3 gastrocutaneous fistulas. Of note, cardiac anesthesia was consulted for all Nissen/GT procedures, and all patients recovered in the cardiac intensive care unit. Fifty-one $(88 \%)$ of the 58 procedures were performed laparoscopically.

\section{Nasogastric Tube Feeding Versus Entirely Oral Feeding}

Of the 278 patients who did not have a Nissen/GT, 190 $(68 \%)$ were discharged from the hospital using at least 
TABLE 2. Nissen/gastrostomy tube or gastrostomy tube alone versus no Nissen/gastrostomy tube: Patient characteristics

\begin{tabular}{|c|c|c|c|}
\hline & $\begin{array}{l}\text { Nissen/ } \\
\text { GT group }\end{array}$ & $\begin{array}{l}\text { No Nissen/ } \\
\text { GT group }\end{array}$ & $\begin{array}{c}P \\
\text { value }\end{array}$ \\
\hline Patient No. & $56(17 \%)$ & $278(83 \%)$ & \\
\hline \multicolumn{4}{|l|}{ Preoperative variables } \\
\hline Weight (kg) & $3.0 \pm 0.5$ & $3.1 \pm 0.5$ & .25 \\
\hline Genetic syndrome $(\mathrm{N}, \%)$ & $13(23 \%)$ & $37(13 \%)$ & .06 \\
\hline Prematurity (N, \%) & $6(11 \%)$ & $36(13 \%)$ & .64 \\
\hline Heterotaxy $(\mathrm{N}, \%)$ & $4(7 \%)$ & $17(6 \%)$ & .76 \\
\hline \multicolumn{4}{|l|}{ Operative variables } \\
\hline Age at surgery (mean $\pm \mathrm{SD}, \mathrm{d})$ & $7 \pm 5$ & $7 \pm 6$ & .68 \\
\hline Norwood procedure (N, \%) & $36(64 \%)$ & $129(46 \%)$ & .02 \\
\hline Pulmonary artery band $(\mathrm{N}, \%)$ & $0(0 \%)$ & $17(6 \%)$ & .06 \\
\hline Blalock-Taussig shunt $(\mathrm{N}, \%)$ & $20(36 \%)$ & $132(48 \%)$ & .11 \\
\hline $\begin{array}{l}\text { Cardiopulmonary bypass operation } \\
(\mathrm{N}, \%)\end{array}$ & $37(66 \%)$ & $148(53 \%)$ & .08 \\
\hline $\begin{array}{l}\text { Cardiopulmonary bypass time } \\
\quad(\text { mean } \pm \mathrm{SD}, \mathrm{min})\end{array}$ & $151 \pm 31$ & $146 \pm 47$ & .44 \\
\hline $\begin{array}{l}\text { Aortic crossclamp time (mean } \pm \\
\text { SD, min) }\end{array}$ & $56 \pm 14$ & $65 \pm 17$ & .003 \\
\hline Circulatory arrest $(\mathrm{N}, \%)$ & $21(37 \%)$ & $82(30 \%)$ & .24 \\
\hline $\begin{array}{l}\text { Circulatory arrest time (mean } \pm \\
\text { SD, min) }\end{array}$ & $6.4 \pm 8.2$ & $5.8 \pm 7.6$ & .74 \\
\hline Delayed sternal closure (N, \%) & $25(45 \%)$ & $76(27 \%)$ & .01 \\
\hline \multicolumn{4}{|l|}{ Postoperative variables } \\
\hline $\begin{array}{l}\text { Mechanical ventilation time (mean } \\
\quad \pm \mathrm{SD}, \mathrm{h})\end{array}$ & $240 \pm 234$ & $158 \pm 177$ & .01 \\
\hline ICU length of stay (mean $\pm \mathrm{SD}$, d) & $20 \pm 18$ & $10 \pm 11$ & $<.001$ \\
\hline $\begin{array}{l}\text { Hospital length of stay (mean } \pm \\
\quad \mathrm{SD}, \mathrm{d} \text { ) }\end{array}$ & $39 \pm 21$ & $17 \pm 15$ & $<.001$ \\
\hline Postoperative arrhythmia (N, \%) & $15(27 \%)$ & $66(24 \%)$ & .63 \\
\hline $\begin{array}{l}\text { Decreased ventricular function at } \\
\text { discharge }(\mathrm{N}, \%)\end{array}$ & $6(10 \%)$ & $25(9 \%)$ & .69 \\
\hline Interstage mortality $(\mathrm{N}, \%)$ & $9(16.1 \%)$ & $17(6.1 \%)$ & .02 \\
\hline
\end{tabular}

$I C U$, Intensive care unit; $S D$, standard deviation.

some NG feeds, and the remaining $88(32 \%)$ were discharged feeding entirely PO. Table 4 lists the comparisons between the 2 groups. Table 5 contains the results of the multivariate analysis. There was no difference in interstage mortality between the 2 groups; the adjusted relative risk of interstage mortality for those patients with a single ventricle without a Nissen/GT but with some NG feeds versus those with all PO feeds was $0.92(95 \% \mathrm{CI}, 0.31-2.73 ; P=.89)$. In the stratified analyses, this estimated relative risk of interstage mortality for those with NG feeds versus those with all PO feeds was similar in both the Norwood group (RR, 0.92 ) and the non-Norwood group (RR, 0.95).

There were 26 total interstage deaths among our 334 patients $(7.8 \%)$, of whom $15(58 \%)$ died after the Norwood procedure and $11(42 \%)$ died after the Blalock-Taussig shunt (there were no cases of interstage death among the 17 patients with a pulmonary artery band). Seven patients died while an inpatient or in the emergency department of Children's Healthcare of Atlanta, with the remaining 19
TABLE 3. Multivariate analysis of interstage mortality risk

\begin{tabular}{lcc}
\hline & Relative risk (95\% CI) & $\boldsymbol{P}$ value \\
\hline $\begin{array}{l}\text { Nissen/GT or GT alone compared } \\
\text { with no Nissen/GT }\end{array}$ & $2.38(1.05-5.40) *$ & .04 \\
*Adjusted for age, weight, genetic syndrome, prematurity, heterotaxy, postoperative \\
arrhythmia, and decreased ventricular function at discharge.
\end{tabular}

patients dying at home or at outside facilities. Of the 7 patients who died within our hospital system, 2 deaths were attributed to complications from recrudescence of pathologic anatomy, specifically a restrictive atrial septum and re-coarctation of the aorta in 2 patients with hypoplastic left heart syndrome. Two other patients had a clotted Blalock-Taussig shunt listed as the cause of death. A single patient died after presenting with severe dehydration due to diarrhea caused by a rotaviral infection. The final 2 patients presented to the emergency department in full arrest and did not have a cause of death ascribed. As for the 19 patients who died at home or at outside facilities, no firm cause of death can be attributed for any of these children. No autopsies were performed. We know that 4 patients were status post-Nissen/GT, 3 patients were status post-GT only, 3 patients were NG feeding at the time, 5 patients were feeding entirely PO, and 4 patients had transitioned from NG tube feeding to entirely feeding PO. The mean time period since last clinic visit for these patients was 6.6 days (range, 1-23 days) with no new pathologic anatomy suspected on the basis of the documentation from those appointments.

\section{DISCUSSION}

Feeding difficulties in newborns after congenital heart surgery are common. Kogon and colleagues ${ }^{12}$ reviewed their postoperative experience and found that $11 \%$ of newborns required a prolonged time to reach goal feeds, $45 \%$ had difficulty transitioning to PO feeds, and $10 \%$ required a surgical procedure, such as a Nissen or G-tube before discharge. Of particular interest, the presence of a single functional ventricle or a systemic to pulmonary artery shunt was a risk factor for such a surgical procedure to facilitate delivery of nutrition. With this in mind, the current study examined neonates after single-ventricle palliation to discern whether the method of feeding at discharge affected interstage mortality.

We first compared patients who were discharged after a Nissen/GT versus all other feeding modalities (NG tube and PO feeding). Although a Nissen/GT has been shown to hasten weight gain in patients with single-ventricle physiology, ${ }^{15}$ limited data exist as to its effects on mortality in this patient population. Our hypothesis was that the Nissen/ GT would protect against interstage mortality by decreasing aspiration-related deaths. Support for this supposition comes from previous studies that concluded that a Nissen fundoplication protects against aspiration in pediatric 
TABLE 4. Nasogastric feeding versus per os feeding: Patient characteristics

\begin{tabular}{|c|c|c|c|}
\hline & $\begin{array}{c}\text { NG } \\
\text { feeding }\end{array}$ & $\begin{array}{l}\text { All PO } \\
\text { feeding }\end{array}$ & $\begin{array}{c}P \\
\text { value }\end{array}$ \\
\hline Patient No. & $190(68 \%)$ & $88(32 \%)$ & \\
\hline \multicolumn{4}{|l|}{ Preoperative variables } \\
\hline Weight $(\mathrm{kg})$ & $3.0 \pm 0.6$ & $3.0 \pm 0.5$ & .87 \\
\hline Genetic syndrome $(\mathrm{N}, \%)$ & $26(14 \%)$ & $11(12 \%)$ & .79 \\
\hline Prematurity $(\mathrm{N}, \%)$ & $26(14 \%)$ & $10(11 \%)$ & .59 \\
\hline Heterotaxy $(\mathrm{N}, \%)$ & $13(7 \%)$ & $4(5 \%)$ & .45 \\
\hline \multicolumn{4}{|l|}{ Operative variables } \\
\hline Age at surgery $($ mean $\pm \mathrm{SD}, \mathrm{d})$ & $7 \pm 6$ & $7 \pm 6$ & .65 \\
\hline Norwood procedure (N, \%) & $100(53 \%)$ & $29(33 \%)$ & .002 \\
\hline Pulmonary artery band $(\mathrm{N}, \%)$ & $10(5 \%)$ & $7(8 \%)$ & .38 \\
\hline Blalock-Taussig shunt $(\mathrm{N}, \%)$ & $80(42 \%)$ & $52(59 \%)$ & .008 \\
\hline $\begin{array}{l}\text { Cardiopulmonary bypass operation } \\
(\mathrm{N}, \%)\end{array}$ & $115(61 \%)$ & $33(37 \%)$ & $<.001$ \\
\hline $\begin{array}{l}\text { Cardiopulmonary bypass time } \\
\quad(\text { mean } \pm \mathrm{SD}, \mathrm{min})\end{array}$ & $148 \pm 49$ & $140 \pm 36$ & .03 \\
\hline $\begin{array}{l}\text { Aortic crossclamp time (mean } \pm \\
\text { SD, min) }\end{array}$ & $66 \pm 16$ & $63 \pm 21$ & .53 \\
\hline Circulatory arrest $(\mathrm{N}, \%)$ & $60(32 \%)$ & $22(25 \%)$ & .26 \\
\hline $\begin{array}{l}\text { Circulatory arrest time (mean } \pm \\
\text { SD, min) }\end{array}$ & $5.8 \pm 8.4$ & $5.9 \pm 4.9$ & .93 \\
\hline Delayed sternal closure (N, \%) & $59(31 \%)$ & $17(19 \%)$ & .04 \\
\hline \multicolumn{4}{|l|}{ Postoperative variables } \\
\hline $\begin{array}{l}\text { Mechanical ventilation time (mean } \\
\quad \pm \mathrm{SD}, \mathrm{h})\end{array}$ & $178 \pm 199$ & $115 \pm 107$ & $<.001$ \\
\hline ICU length of stay (mean $\pm S D, d$ ) & $11 \pm 13$ & $7 \pm 6$ & $<.001$ \\
\hline $\begin{array}{l}\text { Hospital length of stay (mean } \pm \\
\text { SD, d) }\end{array}$ & $18 \pm 16$ & $14 \pm 12$ & .02 \\
\hline Postoperative arrhythmia (N, \%) & $49(26 \%)$ & $17(19 \%)$ & .24 \\
\hline $\begin{array}{l}\text { Decreased ventricular function at } \\
\text { discharge }(\mathrm{N}, \%)\end{array}$ & $21(11 \%)$ & $4(5 \%)$ & .08 \\
\hline Interstage mortality $(\mathrm{N}, \%)$ & $12(6.3 \%)$ & $5(5.4 \%)$ & .78 \\
\hline
\end{tabular}

$I C U$, Intensive care unit; $S D$, standard deviation.

patients in general. ${ }^{16-18}$ In our study, however, there was an increased relative risk of interstage mortality in neonates who underwent a Nissen/GT compared with neonates who did not. Although none of the interstage mortalities were believed to be due to the Nissen procedure itself, we cannot state this with certainty because the majority of our patients died suddenly at home without a subsequent autopsy. Instead, we are left to speculate that the need for a Nissen/ GT in this patient population may be a marker for increased interstage mortality risk rather than a contributing factor itself. In other words, there may be important unmeasured factors in the Nissen/GT group that increase their risk for interstage mortality. Support for this hypothesis comes from the fact that the procedure does nothing to negatively alter known risk factors for interstage mortality (eg, arrhythmias, genetic syndrome, and unbalanced hemodynamics) and is safe to perform in and of itself $(96 \%$ survival to discharge and low complication rate). However, the increased occurrence of interstage mortality in the Nissen/GT cases
TABLE 5. Multivariate analysis of interstage mortality risk

\begin{tabular}{lcc}
\hline & Relative risk $(95 \%$ CI $)$ & P value \\
\hline $\begin{array}{l}\text { NG feeding compared with all } \\
\text { PO feeding }\end{array}$ & $0.92(0.31-2.73)^{*}$ & .89 \\
\hline *Adjusted for age, weight, genetic syndrome, prematurity, heterotaxy, postoperative
\end{tabular}
arrhythmia, and decreased ventricular function at discharge.

remains unnerving. Previous authors have sought to modify interstage mortality by standardization of outpatient care through home-monitoring programs or single-ventricle clinics. ${ }^{19-21}$ Our institutional standard includes frequent scheduled outpatient cardiology appointments and home health nursing assessments. We do not currently rely on data collected by families in our complex patient demographic. Regardless, although the Nissen/GT remains safe to perform (see discussion below) and often the only alternative in patients with recalcitrant GERD with aspiration or failure to thrive, these patients might also represent a select subpopulation who could benefit from more extensive monitoring.

Our data show that with proper multispecialty support, a Nissen/GT is a safe procedure to perform in patients with single-ventricle physiology. This conclusion is congruent with previous studies detailing successful surgical outcomes in other fragile patient populations. ${ }^{22}$ At Children's Healthcare of Atlanta, all patients receive a presurgical consult from cardiac anesthesia and postoperative management in the cardiac intensive care unit. A laparoscopic approach is used in the majority of cases; $88 \%$ of patients received this minimally invasive technique in our study. Compared with an open technique, the benefits of the laparoscopic procedure are decreased recovery time, earlier postoperative feeding, reduced incidence of wound infections, and decreased complications. ${ }^{11,23}$

The current study also examined neonates after singleventricle palliation who were discharged with NG feedings versus those discharged feeding entirely PO. Home NG feeding has been shown to be of limited risk in children (even in high-risk patients) (2, 25 but has never been specifically evaluated in single-ventricle neonates. In the current study, there was no difference in interstage mortality between the 2 groups. This may be related in part to the teaching and support services available at Children's Healthcare of Atlanta. Parents of patients discharged with NG feeding receive standardized teaching regarding tube replacement, feeding pump troubleshooting, formula mixing, and symptoms of feeding intolerance. The format for this teaching includes an instructional video, an instructional booklet, discharge classes, and one-on-one teaching with the nursing staff. Parents are also taught to adjust to progress. For example, in a child expected to rapidly transition to all $\mathrm{PO}$ feedings and being discharged with $\mathrm{PO} / \mathrm{NG}$ hybrid feeds, instructions are that after 48 hours of all PO feedings, the parents could remove the NG tube. With 
similar support in place, we believe that our data demonstrate that discharge with NG feeds does not increase the risk of interstage mortality compared with all PO feeding.

Limitations to this study include those inherent to any retrospective review. Furthermore, limited patient information in some cases prevented ancillary data from being presented. Specifically, we do not know the cause of interstage death in many cases (due to death at home or other hospitals and lack of autopsies). We therefore cannot completely rule out complications from a Nissen/GT as contributive. Finally, it is possible that the lack of difference in mortality, between the NG tube and PO feeding groups, is due to inadequate power (ie, a type II error). Although our analyses suggest that NG tube feeding is safe in this population, large multicenter studies are warranted in an effort to replicate these findings.

\section{CONCLUSIONS}

Neonates with single-ventricle palliative cardiac operations requiring a Nissen/GT have an increased incidence of initial interstage mortality. The Nissen/GT most likely serves as a marker for increased occurrence rather than a contributive factor itself. Regardless, although a Nissen/ GT remains indicated in patients who have significant GERD plus aspiration or failure to thrive, closer scrutiny of the progress of these particular patients should be considered. For patients who do not require a Nissen/GT, discharge with nasogastric feeds does not seem to increase the risk of interstage mortality compared with infants feeding entirely PO.

\section{References}

1. Altmann K, Printa BF, Solowiejczyk DE, et al. Two-dimensional echocardiographic assessment of right ventricular function as a predictor of outcome in hypoplastic left heart syndrome. Am J Cardiol. 2000;86:964-8.

2. Azakie T, Merklinger S, McCrindle BW, et al. Evolving strategies and improving outcomes of the modified Norwood procedure: a 10-year single institution experience. Ann Thorac Surg. 2001;72:1349-53.

3. Fixler DE, Nembhard WN, Salemi JL, et al. Mortality in first 5 years in infants with functional single ventricle born in Texas, 1996-2003. Circulation. 2010; 121:644-50.

4. Forbess JM, Cook N, Roth SJ, et al. Ten-year institutional experience with palliative surgery for hypoplastic left heart syndrome: risk factors related to stage 1 mortality. Circulation. 1995;92:262-6.
5. Kern JH, Hayes CJ, Michler RE, et al. Survival and risk factor analysis for the Norwood procedure for hypoplastic left heart syndrome. Am J Cardiol. 1997; 80:170-4.

6. Mahle WT, Spray TL, Gaynor JW, Clark BJ. Unexpected death after reconstructive surgery for hypoplastic left heart syndrome. Ann Thorac Surg. 2001;76:61-5.

7. Gaynor JW, Mahle WT, Cohen MI, et al. Risk factors for mortality after the Norwood procedure. Eur J Cardiothorac Surg. 2002;22:82-9.

8. Mahle WT, Spray TL, Wernovsky G, Gaynor JW, Clark BJ. Survival after reconstructive surgery for hypoplastic left heart syndrome: a 15-year experience from a single institution. Circulation. 2000;102:136-41.

9. Bartan U, Grunenfelder J, Van Praagh R. Causes of death after the modified Norwood procedure: a study of 122 postmortem cases. Ann Thorac Surg. 1997;64 1795-802.

10. Tweddell JS, Hoffman GM, Mussatto KA, et al. Improved survival of patients undergoing palliation of hypoplastic left heart syndrome: lessons learned from 115 consecutive patients. Circulation. 2002;106:182-9.

11. Peters MJ, Mukhtar A, Yunus RM, et al. Meta-analysis of randomized clinical trials comparing open and laparoscopic anti-reflux surgery. Am J Gastroenterol. 2009; 104:1548-61.

12. Kogon BE, Ramaswamy V, Todd K, et al. Feeding difficulty in newborns following congenital heart surgery. Congenit Heart Dis. 2007;2:332-7.

13. Sano S, Huang SC, Kasahara S, et al. Risk factors for mortality after the Norwood procedure using right ventricle to pulmonary artery shunt. Ann Thorac Surg. 2009;87:178-85

14. Simsic JM, Bradley SM, Stroud MR, Atz AM. Risk factors for interstage death after the Norwood procedure. Pediatr Cardiol. 2005;26:400-3.

15. Cribbs RK, Heiss KF, Clabby ML, Wulkan ML. Gastric fundoplication is effective in promoting weight gain in children with severe congenital heart defects. J Pediatr Surg. 2008;43:283-9.

16. Fokalsrud EW, Bustorff-Silva J, Perez CA, et al. Antireflux surgery in children under 3 months of age. J Pediatr Surg. 1999;34:527-31.

17. Fokalsrud EW, Ashcraft KW, Coran AG, et al. Surgical treatment of gastroesophageal reflux in children: a combined hospital study of 7467 patients. Pediatrics. 1998;101:419-22.

18. Rothenberg SS. Experience with 220 consecutive laparoscopic Nissen fundoplications in infants and children. J Pediatr Surg. 1998;33:274-8.

19. Petit CJ, Fraser CD, Mattamal R, et al. The impact of a dedicated single-ventricle home-monitoring program on interstage somatic growth, interstage attrition, and one-year survival. J Thorac Cardiovasc Surg. 2011;142:1358-66.

20. Dobrolet NC, Nieves J, Welch EM, et al. New approach to interstage care for palliated high-risk patients with congenital heart disease. J Thorac Cardiovasc Surg. 2011;142:855-60.

21. Ghanayem NS, Hoffman GM, Mussatto KA, et al. Home surveillance prevent interstage mortality after the Norwood Procedure. J Thorac Cardiovasc Surg 2003;126:1367-77

22. Shah SR, Jegapragasan M, Fox MD, et al. A review of laparoscopic Nissen fundoplication in children weighing less than $5 \mathrm{~kg}$. J Pediatr Surg. 2010;45:1165-8.

23. Billingham MJ, Basterfield SJ. Pediatric surgical technique: laparoscopic or open approach? A systematic review and meta-analysis. Eur J Pediatr Surg. 2010;20: 73-7.

24. Evans S, Shelton F, Holden C, et al. Monitoring of home safety issues in children on enteral feeds with inherited metabolic disorders. Arch Dis Child. 2010;95 668-72.

25. Holden CE, Puntis JW, Charlton CP, Booth IW. Nasogastric feeding at home: acceptability and safety. Arch Dis Child. 1991;66:148-51. 